\title{
Mortality patterns among workers exposed to acrylamide: 1994 follow up
}

\author{
Gary M Marsh, Lorraine J Lucas, Ada O Youk, Laura C Schall
}

\begin{abstract}
Objective-To update the mortality experience of a cohort of 8508 workers with potential exposure to acrylamide at three plants in the United States from 1984-94.
\end{abstract}

Methods-Analyses of standardised mortality ratios (SMR) with national and local rates and relative risk (RR) regression modelling were performed to assess site specific cancer risks by demographic and work history factors, and exposure indicators for acrylamide and muriatic acid.

Results-For the 1925-94 study period, excess and deficit overall mortality risks were found for cancer sites of interest: brain and other central nervous system (CNS) (SMR 0.65, 95\% confidence interval (95\% CI) 0.36 to 1.09 ), thyroid gland (SMR $2.11,95 \%$ CI 0.44 to 6.17 ), testis and other male genital organs (SMR 0.28, 95\% CI 0.01 to 1.59 ), and cancer of the respiratory system (SMR 1.10, 95\% CI 0.99 to 1.22 ); however, none was significant or associated with exposure to acrylamide. A previously reported excess mortality risk of cancer of the respiratory system at one plant remained increased among workers with potential exposure to muriatic acid (RR $1.50,95 \%$ CI 0.86 to 2.59 ), but was only slightly increased among workers exposed or unexposed to acrylamide. In an exploratory exposure-response analysis of rectal, oesophageal, pancreatic, and kidney cancer, we found increased SMRs for some categories of exposure to acrylamide, but little evidence of an exposureresponse relation. A significant 2.26 -fold risk (95\% CI 1.03 to 4.29$)$ was found for pancreatic cancer among workers with cumulative exposure to acrylamide $>\mathbf{0 . 3 0}$ $\mathrm{mg} / \mathrm{m}^{3}$.years; however, no consistent exposure-response relations were detected with the exposure measures considered when RR regression models were adjusted for time since first exposure to acrylamide.

Conclusion-The contribution of 1115 additional deaths and nearly 60000 personyears over the 11 year follow up period corroborate the original cohort study findings of little evidence for a causal relation between exposure to acrylamide and mortality from any cancer sites, including those of initial interest. This is the most definitive study of the human carcinogenic potential of exposure to acrylamide conducted to date.

(Occup Environ Med 1999;56:181-190)
Keywords: acrylamide; muriatic acid; cohort mortality study

In 1989 , Collins et $a l^{1}$ reported the mortality experience of 8854 workers with potential exposure to acrylamide, a substance widely used in the manufacture of water soluble polymers used for water treating, paper mining, and sugar processing, at four Cytec Industries (formerly the chemical division of American Cyanamid Company), in three United States plants (Fortier, LA; Kalamazoo, MI; and Warners, NJ), and a plant in Botlek, The Netherlands. The original acrylamide study was prompted by animal studies that suggested acrylamide's carcinogenic potential based on an increased incidence of cancers of the brain and central nervous system (CNS), thyroid gland, other endocrine glands, and reproductive organs, ${ }^{23}$ and by limited epidemiological data. Sobel et $a l^{4}$ in a small cohort mortality study of 371 workers exposed to acrylamide, reported 11 observed cancer deaths versus 7.9 expected due to excess cancers of the digestive tract and respiratory system among workers exposed to organic dyes. Among workers not exposed to organic dyes, four cancer deaths were observed versus 6.5 expected.

The original acrylamide study found no significant excesses in total or cause specific mortality between 1925 and 1983 in the four plants. An exposure-response analysis of 2293 workers with exposure to acrylamide showed no trend of increased risk of mortality from several cancer sites. A significant excess in respiratory cancer (SMR 1.31, p < 0.05) was found at the Warners factory, which was largely confined to two groups: men who worked in the muriatic acid operations ( $n=11$ deaths) between 1925 to 1956, and men hired between 1940 to 1949 who had worked less than 1 year in various departments ( $n=52$ deaths). The investigators, including two of the current authors (GMM and LJL) concluded that the results did not support the hypothesis that acrylamide is a human carcinogen. ${ }^{1}$

An extended and updated investigation was undertaken to examine the acrylamide cohort mortality experience from malignant neoplasms relative to exposure to acrylamide, and to investigate the apparent cluster of respiratory cancers at the Warners factory with emphasis on exposure to muriatic acid. We report here the results of an 11 year follow up (1984-94) of the original acrylamide cohort.

Methods

STUDY POPULATION

The original acrylamide cohort included 8854 male employees with full time work experience
Accepted 17 September 1998
Department of Dr G M Marsh, A-410 Crabtree Hall, Graduate University of Pittsburgh, Pittsburgh, PA 15261, USA. 
Table 1 Characteristics of study plants and population used in 1994 update

\begin{tabular}{|c|c|c|c|c|}
\hline Characteristics & Fortier & Kalamazoo & Warners & All plants \\
\hline Plant start up date & 1951 & 1930 & 1917 & - \\
\hline AMD production dates & 1966 present & 1967 present & $1954-85$ & - \\
\hline Total subjects: & 1295 & 60 & 7153 & 8508 \\
\hline White men & 1172 & 57 & 6013 & 7242 \\
\hline Non-white men & 123 & 3 & 1140 & 1266 \\
\hline \multicolumn{5}{|l|}{ Year of birth: } \\
\hline$<1900$ & 1 & 5 & 633 & 639 \\
\hline $1900-19$ & 197 & 15 & 2602 & 2814 \\
\hline $1920-39$ & 724 & 17 & 2908 & 3649 \\
\hline$\geqslant 1940$ & 373 & 23 & 1010 & 1406 \\
\hline \multicolumn{5}{|l|}{ Year of hire (entry into study): } \\
\hline $1925-39$ & 0 & 5 & 1584 & 1589 \\
\hline $1940-49$ & 0 & 12 & 2471 & 2483 \\
\hline $1950-59$ & 730 & 17 & 1566 & 2313 \\
\hline $1960-73$ & 565 & 26 & 1532 & 2123 \\
\hline \multicolumn{5}{|l|}{ Duration of employment (y): } \\
\hline$<1$ & 230 & 6 & 3932 & 4168 \\
\hline $1-4.9$ & 285 & 12 & 1537 & 1834 \\
\hline $5-9.9$ & 133 & 3 & 434 & 570 \\
\hline $10-19.9$ & 248 & 8 & 453 & 709 \\
\hline$\geqslant 20$ & 399 & 31 & 797 & 1227 \\
\hline \multicolumn{5}{|l|}{ Person-years (1925-94): } \\
\hline Total & 40592 & 1884 & 245255 & 287731 \\
\hline Unexposed to AMD & 21320 & 726 & 201781 & 223827 \\
\hline Exposed to AMD* & 19272 & 1158 & 43474 & 63904 \\
\hline $0.001-0.029\left(\mathrm{mg} / \mathrm{m}^{3} . \mathrm{y}\right)$ & 6710 & 328 & 6274 & 13312 \\
\hline $0.03-0.29$ & 11850 & 632 & 12296 & 24778 \\
\hline$\geqslant 0.30$ & 712 & 198 & 24904 & 25814 \\
\hline \multicolumn{5}{|l|}{ Person-years (1950-94): } \\
\hline Total & 40592 & 1778 & 214615 & 256985 \\
\hline Unexposed to AMD & 21320 & 644 & 174467 & 196431 \\
\hline Exposed to AMD* & 19272 & 1134 & 40148 & 60554 \\
\hline $0.001-0.029\left(\mathrm{mg} / \mathrm{m}^{3} . \mathrm{y}\right)$ & 6710 & 328 & 6248 & 13286 \\
\hline $0.03-0.29$ & 11850 & 608 & 11991 & 24449 \\
\hline$\geqslant 0.30$ & 712 & 198 & 21909 & 22819 \\
\hline \multicolumn{5}{|l|}{ Tobacco smoking: } \\
\hline Never smoker & 196 & 4 & 421 & 621 \\
\hline Ever smoker & 550 & 25 & 1558 & 2133 \\
\hline Unknown & 549 & 31 & 5174 & 5754 \\
\hline
\end{tabular}

^Person-years refer to follow up time not exposure time. Person-years among unexposed workers includes follow up time of workers before their first exposure to AMD (started employment in an unexposed job).

Table 2 Vital status of study population by plant: follow up to the end of 1994

\begin{tabular}{lllll}
\hline Vital status & Fortier & Kalamazoo & Warners & All plants \\
\hline Alive: & 987 & 36 & 3777 & 4800 \\
Assumed & 582 & 19 & 2861 & 3462 \\
$\quad$ Confirmed & 405 & 17 & 916 & 1338 \\
Dead: & 288 & 24 & 2970 & 3282 \\
$\quad$ Death certificate (\%) & $280(97)$ & $24(100)$ & $2807(95)$ & $3111(95)$ \\
$\quad$ No death certificate & 8 & 0 & 163 & 171 \\
Unknown (\%) & $20(2)$ & $0(0)$ & $406(6)$ & $426(5)$ \\
\hline
\end{tabular}

at any of the four study plants between 1 January 1925 and 31 January 1973 . In the current update, we did not include the 346 workers from the Botlek plant because the follow up was incomplete at the time of analysis. For the United States plants, company records were reviewed to update the work histories and the exposures to acrylamide and muriatic acid of study members actively employed at the end of 1983. The United States study cohort includes 8508 workers.

Table 1 shows selected characteristics of the United States study population by plant. The Warners factory is the oldest and largest plant in the study contributing $84 \%$ of the total study members and person-years. About half of the cohort was hired before 1950 and employed at the Warners or Kalamazoo plants, and about half were short term workers (defined as $<1$ year of employment). Most of the cohort members in each plant are white. Because of incomplete data, tobacco smoking history had limited use as a covariable in the original exposure-response analysis and now.
COHORT TRACING

The vital status of the United States study members was determined as of 31 December 1994 with Cytec personnel and pension files and based on a two stage tracing protocol that uses several conventional tracing sources, including the Social Security Administration and the National Death Index. ${ }^{5}$ Consistent with our protocol, all people who died after the 1994 follow up period or who were traced and not identified as deceased during the study period were assumed to be alive as of the study end date. Those with unknown vital status were untraceable due to missing Social Security numbers, a methodological limitation of the original study due mostly to Warners employees who started work before the establishment of Social Security. Death certificates were obtained from the corresponding state health department, and to conform with the original study, were coded by a nosologist to the underlying cause of death with the 8th revision rules of the international classification of diseases (ICD-8).

Table 2 shows the plant specific vital status of the United States study population at the end of 1994. A total of 3282 deaths as identified through 1994, an increase of 1115 deaths from the original 1983 follow up of the United States plants. People lost to follow up decreased from $513(6 \%)$ in the original study to $426(5 \%)$. Death certificates were obtained for 3111 $(95 \%)$ of all deaths.

EXPOSURE ESTIMATES

Acrylamide

The general methods of the quantitative estimates of exposure to acrylamide detailed by Collins et al $l^{1}$ considered a worker as exposed to acrylamide if his cumulative exposure value is $>0.001 \mathrm{mg} / \mathrm{m}^{3}$.years, the approximate equivalent exposure of a 1 day average concentration to the current permissible exposure limit of $0.3 \mathrm{mg} / \mathrm{m}^{3}$. From the individual worker job histories and the job and time specific exposure estimates, three time dependent summary measures of exposure to acrylamide, were computed for each worker:

- Duration of exposure=the sum of the days spent in jobs with non-zero exposure to acrylamide (y)

- Cumulative exposure=the product of the number of days in each job and the estimated average daily exposure to acrylamide, summed across all jobs $\left(\mathrm{mg} / \mathrm{m}^{3} . \mathrm{y}\right)$

- Average intensity of exposure=the ratio of cumulative to duration $\left(\mathrm{mg} / \mathrm{m}^{3}\right)$

Exposure estimates for the 1984-94 period were assigned with the 1983 exposures to acrylamide developed in the original study. Few employees in the follow up period would have potential exposure to acrylamide, as the Warners plant stopped acrylamide operations in 1985 and any extrapolation error would be small with minimal impact on our findings. This conservative operating assumption was also supported by a review of industrial hygiene monitoring data and by plant personnel, including one coauthor (LJL), knowledgeable 
Table 3 Summary statistics for exposure measures to AMD and muriatic acid by plant, all workers, 1925-94

\begin{tabular}{|c|c|c|c|c|}
\hline Exposure indicator* & Fortier & Kalamazoo & Warners & All plants \\
\hline \multicolumn{5}{|l|}{ Acrylamide: } \\
\hline \multicolumn{5}{|l|}{ Duration of exposure $(y)$ : } \\
\hline Minimum & 0 & 0 & 0 & 0 \\
\hline 25th percentile & 0 & 0 & 0 & 0 \\
\hline Median & 0 & 2.62 & 0 & 0 \\
\hline 75 th percentile & 5.40 & 15.58 & 0 & 0 \\
\hline Maximum & 34.62 & 41.67 & 40.99 & 41.67 \\
\hline Mean & 4.16 & 7.62 & 1.20 & 1.69 \\
\hline SD & 7.25 & 9.68 & 4.79 & 5.42 \\
\hline Coefficient of variation & 174.3 & 127.1 & 400.5 & 319.9 \\
\hline \multicolumn{5}{|c|}{ Average intensity of exposure $\left(\mathrm{mg} / \mathrm{m}^{3}\right)$ : } \\
\hline Minimum & 0 & 0 & 0 & 0 \\
\hline 25 th percentile & 0 & 0 & 0 & 0 \\
\hline Median & 0 & 0.003 & 0 & 0 \\
\hline 75 th percentile & 0.010 & 0.008 & 0 & 0 \\
\hline Maximum & 0.055 & 0.124 & 2.200 & 2.200 \\
\hline Mean & 0.007 & 0.009 & 0.115 & 0.098 \\
\hline SD & 0.011 & 0.019 & 0.364 & 0.336 \\
\hline Coefficient of variation & 157.2 & 201.8 & 315.8 & 342.7 \\
\hline \multicolumn{5}{|c|}{ Cumulative exposure $\left(\mathrm{mg} / \mathrm{m}^{3} \cdot \mathrm{y}\right)$} \\
\hline Minimum & 0 & 0 & 0 & 0 \\
\hline 25 th percentile & 0 & 0 & 0 & 0 \\
\hline Median & 0 & 0.02 & 0 & 0 \\
\hline 75 th percentile & 0.06 & 0.08 & 0 & 0 \\
\hline Maximum & 0.81 & 0.72 & 32.31 & 32.31 \\
\hline Mean & 0.04 & 0.08 & 0.29 & 0.25 \\
\hline SD & 0.08 & 0.15 & 1.34 & 1.23 \\
\hline Coefficient of variation & 190.7 & 180.8 & 458.3 & 487.6 \\
\hline \multicolumn{5}{|l|}{ Muriatic acid; } \\
\hline \multicolumn{5}{|l|}{ Duration of exposure (y): } \\
\hline Minimum & & & 0 & \\
\hline 25 th percentile & & & 0 & \\
\hline Median & & & 0 & \\
\hline 75 th percentile & & & 0 & \\
\hline Maximum & & & 26.53 & \\
\hline Mean & & & 0.08 & \\
\hline SD & & & 1.02 & \\
\hline Coefficient of variation & & & 1256.4 & \\
\hline
\end{tabular}

${ }^{\star}$ Computed from date of hire to earliest of date of ending work, death, or 31 December 1994.

of acrylamide processes during the follow up period.

Muriatic acid

Muriatic acid production operated only at the Warners plant between 1922 and 1937; between 1937 and 1956 muriatic acid exposure was restricted to trans-shipment and repackaging. Duration of exposure was the only muriatic acid exposure measure computed as only a qualitative estimate was assessed (presence or absence of potential exposure for each job).

Table 3 shows selected summary statistics for the three measures of exposure to acrylamide computed for all workers in the 1994 acrylamide cohort and for duration of exposure to muratic acid at Warners. For all workers combined, 60554 (24\%) of the total personyears are associated with exposure to acrylamide (table 1). The values of each exposure measure are generally small, consistent with the observation in table 1 that nearly half of the study members were short term workers. For example, at Warners, the mean intensity of exposure to acrylamide was 0.115 and the mean duration of exposure to muratic acid was only 0.08 years.

Exposure to acrylamide varied, as each of the domestic plants produced or used acrylamide differently. Acrylamide is produced in two forms, wet acrylamide in aqueous solution, and dry acrylamide that can be in either a powder or a solid pellet. The Warners plant produced both forms of acrylamide. The Fortier factory manufactured wet acrylamide monomer. Both plants used wet and dry acrylamide in the formulation of other products. Kalamazoo used only wet acrylamide. Potential exposure may have occurred during monomer and polymer production from inhalation of dry powder, acrylamide monomer, or aerosols of acrylamide solution and dermal absorption of the acrylamide monomer and solutions.

\section{STATISTICAL ANALYSES}

Descriptive analysis of SMRs

We examined the total and cause specific mortality experiences of the United States acrylamide cohort from 1 January 1925 to 31 December 1994. Cohort analyses were performed with a modified life table procedure from the occupational cohort mortality programme (OCMAP). ${ }^{6-8}$ Person-years at risk contributed by each study member were jointly classified by plant, race, age group, calendar time, duration of employment (DOE), and the time since first employment (TSFE). Personyear counts began at the date of hire and continued until date of death or the end of the 1994 study period. For workers lost to follow up, person-year counts stopped at the last date of known vital status, which was always the date of the end of employment.

We computed expected numbers of deaths by multiplying average annual race, age, and time specific standard population death rates by the person-years at risk in the corresponding race age time intervals. To coincide with update periods, 1980-4 rates were applied to 1980-3 person-years and 1985-9 rates were applied to 1984-9 person-years. As in the original study, expected numbers of deaths for the United States plants were computed with the total United States male population as the standard population. United States male death rates covering the 1925-89 observation period were obtained from the cohort analysis software developed by Monson. ${ }^{9}$ For the 1990-4 period, corresponding United States rates were obtained for comparable categories from the mortality and population data system (MPDS) maintained at the University of Pittsburgh. ${ }^{10}$

As an enhancement to the original study, we computed expected numbers of deaths based on MPDS rates for the male populations of the counties surrounding the factory (for WarnersMiddlesex and Union Counties, NJ) or the local county in which the subcohort largely resides (for Fortier-Jefferson Parish, LA; for Kalamazoo-Kalamazoo County, MI). Due to limitations of the MPDS data, expected numbers of cancer deaths were limited to the period 1950-94; non-cancer deaths were limited to $1960-94$ (with 1962-4 rates applied to 1960-4 person-years). MPDS rates were used only for those cause of death categories defined by identical or nearly identical ICD codes in the Monson and MPDS rate files. Because local death rates usually provide the most valid external mortality comparisons (as they help to adjust for the social, cultural, and economic factors related to disease), all but the aggregate analysis were based exclusively on local rates. Moreover, because the counties involved repre- 
sent large population areas, the local rates are measured with good precision.

Mortality excesses and deficits were expressed as standardised mortality ratios (SMRs) along with their 95\% confidence intervals (95\% CIs). The SMRs were computed for subgroups of the cohort defined by plant, race, follow up period, calendar period, year of hire, duration of employment, and the time since first employment. The SMRs were also computed for selected causes of death for the measures of exposure categories of acrylamide and muriatic acid with and without exposure lagging. ${ }^{811}$ Here, person-year counts in the unexposed baseline categories include the observation time of workers before their first exposure. The significance of SMRs was assessed with Poisson probabilities. All tests were done at the 0.05 significance level and no adjustment was made for multiple comparisons.

\section{Relative risk regression analysis}

Relative risk regression modelling was used to investigate the dependence of the internal cohort rates (modelled as time to death) for selected cancer sites on combinations of the categorical acrylamide or muriatic acid exposure measures, with adjustment for potential confounding factors. Study data from the entire 1925-94 period were modelled. For each cancer site examined, risk sets were explicitly constructed from the cohort data file with age as the primary time dimension, with the RISKSET program module in OCMAP-PLUS. ${ }^{8}$ To adjust for year of birth (cohort) effects, risk sets were caliper matched on year of birth. The time dependent exposures were evaluated for each person at each event time they were at risk.

Multiplicative relative risk (RR) models of the form $\lambda(\mathrm{t})=\lambda_{0}(\mathrm{t}) \exp \{\mathrm{x}(\mathrm{t}) \beta\}$ were fitted to the internal cohort rates. Mathematical details of the models are given elsewhere. ${ }^{12-14}$ The conditional logistic regression program in EGRET $^{15}$ was used to estimate $\beta$ from the explicitly constructed risk sets. Categorised forms of the covariates were considered to parallel the descriptive SMR analysis of mortality relative to exposure. The demographic and exposure variables were first considered univariately as categorical variables to identify patterns of univariate associations with the outcome and sparse data problems. Possible exposure-disease associations were then evaluated with a forward stepwise approach to adjust for possible confounders. Effect modification was assessed as far as possible.

The significance of each main effect (expressed as a global $p$ value) and interaction was assessed with a likelihood ratio statistic. For the quantitative exposure variables that had a monotonic pattern in the parameter estimates, a test for linear trend was conducted (expressed as a trend $\mathrm{p}$ value). All tests were done at the 0.05 significance level with no adjustment made for multiple comparisons.

\section{Results}

GENERAL MORTALITY BY STUDY PERIOD

Table 4 presents SMRs by cause and study period for the combined 1994 United States acrylamide cohort (some findings for the 1925-83 period differ slightly from those

Table 4 Observed deaths and SMRs for selected causes by follow up period, all workers, national comparisons

\begin{tabular}{|c|c|c|c|c|c|c|c|c|c|}
\hline \multirow[b]{2}{*}{ Cause of death $(I C D A-8)+$} & \multicolumn{3}{|c|}{$1925-83$} & \multicolumn{3}{|c|}{ 1984-94 } & \multicolumn{3}{|c|}{$1925-94$} \\
\hline & Obs & $S M R$ & $95 \% C I$ & Obs & $S M R$ & $95 \% C I$ & Obs & $S M R$ & $95 \% C I$ \\
\hline All causes (000-999): & 2167 & $0.91^{\star \star}$ & 0.87 to 0.95 & 1115 & \multicolumn{2}{|c|}{$0.76^{\star \star} 0.72$ to 0.81} & 3282 & $0.85^{\star \star}$ & 0.82 to 0.88 \\
\hline All malignant neoplasms (140-209) & 496 & 1.06 & 0.96 to 1.15 & 357 & $0.89^{\star}$ & 0.80 to 0.99 & 853 & 0.98 & 0.92 to 1.05 \\
\hline Buccal cavity and pharynx $(140-149)$ & 13 & 0.83 & 0.44 to 1.42 & 8 & 0.96 & 0.41 to 1.89 & 21 & 0.88 & 0.54 to 1.34 \\
\hline Digestive organs and peritoneum (150-159) & 141 & 1.07 & 0.90 to 1.26 & 85 & 0.89 & 0.71 to 1.10 & 226 & 0.99 & 0.87 to 1.13 \\
\hline Oesophagus (150) & 16 & 1.15 & 0.66 to 1.87 & 15 & 1.30 & 0.73 to 2.14 & 31 & 1.22 & 0.83 to 1.73 \\
\hline Stomach (151) & 35 & 1.34 & 0.94 to 1.87 & 12 & 0.95 & 0.49 to 1.66 & 47 & 1.22 & 0.89 to 1.62 \\
\hline Large intestine (153) & 38 & 0.94 & 0.67 to 1.29 & 28 & 0.78 & 0.52 to 1.13 & 66 & 0.87 & 0.67 to 1.10 \\
\hline Rectum (154) & 16 & 1.20 & 0.69 to 1.95 & 8 & 1.26 & 0.55 to 2.49 & 24 & 1.22 & 0.78 to 1.82 \\
\hline Liver $(155,156)$ & 5 & 0.51 & 0.16 to 1.20 & 5 & 0.58 & 0.19 to 1.35 & 10 & 0.55 & 0.26 to 1.00 \\
\hline Pancreas (157) & 27 & 1.09 & 0.72 to 1.59 & 17 & 0.91 & 0.53 to 1.46 & 44 & 1.01 & 0.74 to 1.36 \\
\hline Respiratory system $(160-163)$ & 202 & $1.25^{\star \star}$ & 1.08 to 1.44 & 139 & 0.94 & 0.79 to 1.11 & 341 & 1.10 & 0.99 to 1.22 \\
\hline Larynx (161) & 8 & 1.10 & 0.48 to 2.18 & 6 & 1.25 & 0.46 to 2.71 & 14 & 1.16 & 0.63 to 1.95 \\
\hline Lung $(162,163)$ & 194 & $1.27^{\star \star}$ & 1.10 to 1.46 & 133 & 0.94 & 0.78 to 1.11 & 327 & 1.11 & 0.99 to 1.24 \\
\hline Bone (170) & 2 & 0.88 & 0.11 to 3.18 & 0 & - & 0.00 to 6.19 & 2 & 0.70 & 0.08 to 2.52 \\
\hline Skin $(172,173)$ & 4 & 0.48 & 0.13 to 1.23 & 6 & 0.89 & 0.33 to 1.93 & 10 & 0.66 & 0.31 to 1.22 \\
\hline Prostate (185) & 29 & 0.96 & 0.64 to 1.38 & 38 & 0.82 & 0.58 to 1.13 & 67 & 0.88 & 0.68 to 1.11 \\
\hline Testis and other male genital organs $(186,187)$ & 0 & - & 0.00 to 1.23 & 1 & 1.92 & 0.05 to 10.70 & 1 & 0.28 & 0.01 to 1.59 \\
\hline Bladder (188) & 13 & 1.06 & 0.56 to 1.81 & 14 & 1.38 & 0.75 to 2.31 & 27 & 1.20 & 0.79 to 1.75 \\
\hline Kidney (189) & 12 & 1.06 & 0.55 to 1.86 & 10 & 1.11 & 0.53 to 2.04 & 22 & 1.08 & 0.68 to 1.64 \\
\hline Brain and other central nervous system $(191,192)$ & 5 & $0.36^{\star}$ & 0.12 to 0.85 & 9 & 1.15 & 0.53 to 2.19 & 14 & 0.65 & 0.36 to 1.09 \\
\hline Thyroid gland (193) & 2 & 2.32 & 0.28 to 8.37 & 1 & 1.80 & 0.04 to 10.01 & 3 & 2.11 & 0.44 to 6.17 \\
\hline All lymphopoietic tissue (200-209) & 39 & 0.88 & 0.62 to 1.20 & 21 & $0.60^{\star}$ & 0.37 to 0.92 & 60 & $0.76^{\star}$ & 0.58 to 0.97 \\
\hline Lymphosarcoma and reticulosarcoma (200) & 6 & 0.70 & 0.26 to 1.53 & 0 & - & 0.00 to 2.35 & 6 & 0.59 & 0.22 to 1.29 \\
\hline Hodgkin's disease (201) & 8 & 1.39 & 0.60 to 2.74 & 0 & - & 0.00 to 4.04 & 8 & 1.20 & 0.52 to 2.37 \\
\hline Leukaemia and aleukaemia (204-207) & 14 & 0.78 & 0.43 to 1.31 & 9 & 0.68 & 0.31 to 1.29 & 23 & 0.74 & 0.47 to 1.10 \\
\hline Other lymphatic tissue $(202,203,208)$ & 11 & 0.92 & 0.46 to 1.66 & 11 & 0.65 & 0.32 to 1.16 & 22 & 0.76 & 0.48 to 1.16 \\
\hline Benign neoplasms (210-239) & 8 & 1.24 & 0.54 to 2.44 & 2 & 0.60 & 0.07 to 2.15 & 10 & 1.02 & 0.49 to 1.87 \\
\hline Diabetes mellitus (250) & 26 & 0.77 & 0.50 to 1.12 & 15 & $0.53^{\star \star}$ & $\star 0.30$ to 0.87 & 41 & $0.66^{\star \star}$ & 0.47 to 0.89 \\
\hline Diseases of the circulatory system $(390-458)$ & 1019 & $0.90^{\star \star}$ & 0.85 to 0.96 & 434 & $0.61^{\star \star}$ & $\star 0.56$ to 0.67 & 1453 & $0.79^{\star \star}$ & 0.75 to 0.83 \\
\hline Non-malignant respiratory disease $(460-519)$ & 105 & $0.75^{\star \star}$ & 0.62 to 0.91 & 74 & $0.53^{\star \star}$ & $\star 0.42$ to 0.67 & 179 & $0.64^{\star \star}$ & 0.55 to 0.74 \\
\hline Cirrhosis of the liver (571) & 68 & 1.08 & 0.84 to 1.37 & 12 & $0.54^{\star}$ & 0.28 to 0.94 & 80 & 0.94 & 0.74 to 1.17 \\
\hline All external causes of death (800-998) & 199 & $0.70^{\star \star}$ & 0.61 to 0.81 & 43 & $0.65^{\star \star}$ & $\star 0.47$ to 0.87 & 242 & $0.69^{\star \star}$ & 0.61 to 0.79 \\
\hline Unknown causes (999.9) & 101 & & & 70 & & & 171 & & \\
\hline People (n) & & 85 & & & 594 & & & 850 & \\
\hline Person-years & & 2288 & & & 5891 & & & 28773 & \\
\hline
\end{tabular}

${ }^{\star} \mathrm{p}<0.05 ;{ }^{\star \star} \mathrm{p}<0.01$

†Monson life table programme ICD-8 categories, labels, and codes for US plants for 1925-89; corresponding MPDS rates for 1990-4. 
Table 5 Observed deaths and SMRs for selected cancer sites by plant, US workers, 1950-94, local county comparison

\begin{tabular}{|c|c|c|c|c|c|c|c|c|c|}
\hline \multirow[b]{2}{*}{ Cause of death $(I C D A-8)+$} & \multicolumn{3}{|c|}{ Fortier } & \multicolumn{3}{|c|}{ Kalamazoo } & \multicolumn{3}{|c|}{ Warners } \\
\hline & Obs & $S M R$ & $95 \% C I$ & Obs & $S M R$ & $95 \% C I$ & Obs & $S M R$ & $95 \% C I$ \\
\hline All malignant neoplasms (140-209) & 99 & 0.93 & 0.76 to 1.14 & 6 & 1.03 & 0.38 to 2.24 & 736 & $0.91^{\star \star}$ & 0.84 to 0.97 \\
\hline Buccal cavity and pharynx (140-149) & 4 & 1.32 & 0.36 to 3.39 & 0 & - & 0.00 to 24.72 & 17 & 0.75 & 0.44 to 1.20 \\
\hline Digestive organs and peritoneum $(150-159)$ & 23 & 1.04 & 0.66 to 1.56 & 0 & - & 0.00 to 2.49 & 198 & $0.83^{\star \star}$ & 0.72 to 0.96 \\
\hline Oesophagus (150) & 4 & 1.41 & 0.38 to 3.61 & 0 & - & 0.00 to 33.01 & 27 & 1.00 & 0.66 to 1.45 \\
\hline Stomach (151) & 4 & 1.37 & 0.37 to 3.56 & 0 & - & 0.00 to 11.91 & 40 & 0.89 & 0.63 to 1.21 \\
\hline Large intestine (153) & 8 & 1.01 & 0.44 to 1.99 & 0 & - & 0.00 to 8.11 & 58 & $0.69^{\star \star}$ & 0.52 to 0.89 \\
\hline Rectum (154) & 1 & 0.58 & 0.01 to 3.22 & 0 & - & 0.00 to 20.91 & 21 & 0.93 & 0.58 to 1.42 \\
\hline Pancreas (157) & 6 & 1.36 & 0.50 to 2.96 & 0 & - & 0.00 to 12.58 & 38 & 0.94 & 0.66 to 1.28 \\
\hline Respiratory system (160-163) & 36 & 0.78 & 0.55 to 1.08 & 4 & 1.95 & 0.53 to 4.99 & 298 & 1.11 & 0.98 to 1.24 \\
\hline Bronchus, trachea, lung (162) & 34 & 0.77 & 0.54 to 1.08 & 4 & 2.02 & 0.55 to 5.16 & 284 & 1.11 & 0.99 to 1.25 \\
\hline Prostate (185) & 3 & 0.52 & 0.11 to 1.52 & 1 & 1.86 & 0.04 to 10.34 & 63 & 0.85 & 0.66 to 1.09 \\
\hline \multicolumn{10}{|l|}{ Testis and other male genital organs $(172.5$, } \\
\hline $173.5,186,187) \ddagger$ & 0 & - & 0.00 to 10.88 & 0 & - & 0.00 to 129.95 & 2 & 0.81 & 0.10 to 2.91 \\
\hline Bladder and other urinary organs $(188,189.9) \ddagger$ & 2 & 1.08 & 0.13 to 3.89 & 0 & - & 0.00 to 19.71 & 25 & 1.02 & 0.66 to 1.50 \\
\hline Kidney $(189.0,189.1,189.2) \ddagger$ & 3 & 0.98 & 0.20 to 2.87 & 1 & 6.95 & 0.17 to 38.70 & 18 & 0.89 & 0.53 to 1.41 \\
\hline Central nervous system $(191,192)$ & 5 & 1.80 & 0.59 to 4.21 & 0 & - & 0.00 to 22.57 & 9 & $0.49^{\star}$ & 0.22 to 0.93 \\
\hline \multicolumn{10}{|l|}{ Thyroid gland and other endocrine glands (193, } \\
\hline 194$) \ddagger$ & 1 & 3.93 & 0.10 to 21.91 & 0 & - & 0.00 to 291.70 & 5 & 2.17 & 0.71 to 5.07 \\
\hline \multicolumn{10}{|l|}{ All lymphatic and haematopoietic tissue } \\
\hline$(200-209)$ & 11 & 1.30 & 0.65 to 2.32 & 0 & - & 0.00 to 5.96 & 46 & $0.66^{\star \star}$ & 0.48 to 0.88 \\
\hline Leukaemia and aleukaemia (204-207) & 2 & 0.63 & 0.08 to 2.27 & 0 & - & 0.00 to 17.75 & 21 & 0.80 & 0.50 to 1.23 \\
\hline $\begin{array}{l}\text { Other lymphopoietic tissue }(202,203,208 \text {, } \\
209) \ddagger\end{array}$ & 8 & 2.31 & 0.99 to 4.54 & 0 & - & 0.00 to 13.68 & 14 & $0.50^{\star}$ & 0.28 to 0.85 \\
\hline
\end{tabular}

${ }^{\star} \mathrm{p}<0.051 ;{ }^{\star \star} \mathrm{p}<0.01$.

†MPDS ICD-8 categories, labels and codes for US plants.

$\ddagger$ MPDS ICD codes differ from corresponding Monson codes.

reported by Collins et al $1^{1}$ due to the cohort data revisions noted above). During the 1984-94 update period there were 1115 deaths, yielding a significant $(\mathrm{p}<0.01) 24 \%$ overall deficit in total mortality compared with the general United States population. For the overall 1925-94 study period, there was a significant $(\mathrm{p}<0.01) 15 \%$ deficit in total mortality based on 3282 observed deaths and 287731 personyears.

The SMRs for all malignant neoplasms combined and for many cancer site specific categories also decreased in the 1984-94 update period. In particular, cancer of the respiratory system decreased from a significant $(\mathrm{p}<0.01) 25 \%$ excess in mortality for the 1925-83 period to a 6\% deficit (based on 139 cancer of the respiratory system deaths), resulting in a non-significant $10 \%$ excess for the combined 1925-94 study period. Most of the deaths from cancer of the respiratory system were due to lung cancer.

For the other cancer sites of initial interest in the combined study period (table 4), we found deficits in deaths for cancer of the brain and other parts of the CNS (SMR 0.65, 95\% CI 0.36 to 1.09 ) and cancer of the testis and other male genital organs (SMR 0.28, 95\% CI 0.01 to 1.59). A non-significant excess in cancer of the thyroid gland was based on three deaths (SMR 2.11, 95\% CI 0.44 to 6.17). The SMR for thyroid cancer decreased to 1.80 in the 1984-94 update period. Most of the nonmalignant cause of death categories shown in table 4 showed deficits in deaths for the update and combined study periods and many deficits were significant $(p<0.05)$. The SMRs for some cancer site specific categories increased in the update period; however, none of the resulting excesses in the update or combined study periods was significant.

Although not shown here, SMR analyses by race, period, year of employment and duration of employment were essentially unremarkable for the initial cancer sites and the other cause of death categories examined in table 4 .

\section{GENERAL MORTALITY BY PLANT}

Table 5 shows the 1950-94 cancer mortality experience of workers from each United States plant compared with the local male populations. Restricting the observation period excluded only 12 cancer deaths, all from the Warners plant. Shown are the cancer site categories of initial interest (brain and other parts of the CNS, thyroid and other endocrine glands, and testis and other male genital organs) or sites with at least 20 observed deaths across the three plants. For certain categories (thyroid and other endocrine glands), the observed number of deaths differs between tables 4 and 5 due to the slight variations in the ICD codes used in the MPDS and Monson rates.

Table 5 shows that $736(88 \%)$ of the observed cancer deaths occurred at Warners (SMR 0.91, 95\% CI 0.84-.97), whereas only six occurred at Kalamazoo (SMR 1.03, 95\% CI 0.38 to 2.24 ). None of the plants show significant excess in mortality at any specific cancer site. Among the initial sites, non-significant excesses in deaths occurred at Fortier for brain and other parts of the CNS (SMR 1.80, 95\% CI 0.59 to 4.21 ) and thyroid and other endocrine glands at Fortier (SMR 3.93, 95\% CI 0.10 to 21.91), and at Warners (SMR 2.17, $95 \%$ CI 0.71 to 5.07$)$. The two deaths from cancer of the testis and other male genital organs occurred at Warners resulting in a $19 \%$ deficit (SMR 0.81, 95\% CI 0.10 to 2.91).

\section{CANCER MORTALITY BY EXPOSURE TO} ACRYLAMIDE

Table 6 depicts the 1950-94 cancer mortality experience of all United States workers compared with those with exposure to acrylamide for the selected cancer sites examined in table 5. Consistent with original study results, we found deficits compared with local county 
Table 6 Observed deaths and SMRs for selected cancer sites by exposure to acrylamide, US workers, 1950-94, local county comparison

\begin{tabular}{|c|c|c|c|c|c|c|}
\hline \multirow[b]{2}{*}{ Cause of death $(I C D A-8)+$} & \multicolumn{3}{|c|}{ Unexposed $\left(<0.001 \mathrm{mg} / \mathrm{m}^{3} \cdot y\right)$} & \multicolumn{3}{|c|}{ Exposed $\left(\geqslant 0.001 \mathrm{mg} / \mathrm{m}^{3} \cdot \mathrm{y}\right)$} \\
\hline & Obs & $S M R$ & $95 \% C I$ & Obs & $S M R$ & $95 \% C I$ \\
\hline All malignant neoplasms (140-209) & 681 & $0.89^{\star \star}$ & 0.83 to 0.96 & 160 & 0.98 & 0.83 to 1.14 \\
\hline Buccal cavity and pharynx (140-149) & 18 & 0.85 & 0.50 to 1.34 & 3 & 0.65 & 0.13 to 1.89 \\
\hline Digestive organs and peritoneum (150-159) & 177 & $0.81^{\star \star}$ & 0.70 to 0.94 & 44 & 1.03 & 0.75 to 1.38 \\
\hline Oesophagus (150) & 24 & 0.96 & 0.61 to 1.42 & 7 & 1.41 & 0.57 to 2.90 \\
\hline Stomach (151) & 39 & 0.95 & 0.68 to 1.30 & 5 & 0.69 & 0.22 to 1.60 \\
\hline Large intestine (153) & 55 & $0.72^{\star}$ & 0.54 to 0.93 & 11 & 0.71 & 0.36 to 1.28 \\
\hline Rectum (154) & 17 & 0.82 & 0.48 to 1.32 & 5 & 1.33 & 0.43 to 3.09 \\
\hline Pancreas (157) & 30 & 0.80 & 0.54 to 1.14 & 14 & 1.79 & 0.98 to 3.01 \\
\hline Respiratory system (160 to 163 ) & 276 & 1.07 & 0.95 to 1.20 & 62 & 1.04 & 0.79 to 1.33 \\
\hline Bronchus, trachea, lung (162) & 260 & 1.07 & 0.94 to 1.20 & 62 & 1.09 & 0.84 to 1.40 \\
\hline Prostate (185) & 60 & 0.88 & 0.67 to 1.14 & 7 & 0.58 & 0.23 to 1.19 \\
\hline \multicolumn{7}{|l|}{ Testis and other male genital organs $(172.5,173.5,186$, } \\
\hline 187) & 2 & 0.86 & 0.10 to 3.10 & 0 & - & 0.00 to 7.09 \\
\hline Bladder and urinary organs $(188,189.9)$ & 22 & 0.98 & 0.61 to 1.48 & 5 & 1.19 & 0.39 to 2.77 \\
\hline Kidney $(189.0,189.1,189.2)$ & 16 & 0.84 & 0.48 to 1.37 & 6 & 1.36 & 0.50 to 2.96 \\
\hline Central nervous system $(191,192)$ & 11 & 0.64 & 0.32 to 1.14 & 3 & 0.74 & 0.15 to 2.15 \\
\hline Thyroid gland and other endocrine glands $(193,194)$ & 4 & 1.91 & 0.52 to 4.88 & 2 & 4.27 & 0.52 to 15.42 \\
\hline All lymphatic and haematopoietic tissue (200-209) & 43 & $0.67^{\star \star}$ & 0.48 to 0.90 & 14 & 0.98 & 0.54 to 1.64 \\
\hline Leukaemia and alaeukaemia (204-207) & 17 & 0.70 & 0.41 to 1.12 & 6 & 1.15 & 0.42 to 2.51 \\
\hline Other lymphopoietic tissue $(202,203,208,209)$ & 16 & 0.63 & 0.36 to 1.02 & 6 & 1.00 & 0.37 to 2.18 \\
\hline People (n) & \multicolumn{3}{|c|}{7532} & \multicolumn{3}{|c|}{2004} \\
\hline Person-years & \multicolumn{3}{|c|}{202409} & \multicolumn{3}{|c|}{54576} \\
\hline
\end{tabular}

${ }^{\star} \mathrm{p}<0.05 ;{ }^{\star \star} \mathrm{p}<0.01$.

†MPDS ICD-8, labels, and codes for US plants.

cancer mortality among both exposed and unexposed workers for all cancers combined and many specific cancer sites, including brain and other parts of the CNS, and testis and other male genital organs. Although the original study reported a significant $(p<0.05) 31 \%$ excess for cancer of the respiratory system among unexposed workers (and 14\% among those exposed), we now found that up to the end of 1994 only slight non-significant $7 \%$ and $4 \%$ excesses for cancer of the respiratory system among the unexposed and exposed groups, respectively. These decreased SMRs follow from the overall reduction in mortality from cancer of the respiratory system during the 1984-94 follow up period noted in table 4 . For the initial site, cancer of thyroid and other endocrine glands, a non-significant increased mortality risk was found among both unexposed (SMR 1.91, 95\% CI 0.52 to 4.88 ) and exposed (SMR 4.27, 95\% CI 0.52 to 15.42 ) workers.

EXPLORATORY EXPOSURE-RESPONSE ANALYSIS OF SMRS

Four cancer sites-rectum, oesophagus, pancreas, and kidney-were selected for more detailed exploratory exposure-response analyses based on $a \geqslant 20 \%$ excesses in mortality in exposed workers and deficits in unexposed workers (table 6); none of these excesses was significant. Table 7 shows observed deaths and SMRs based on local rates (1950-94) for the four cancer sites by duration of employment, the time since first employment, and the three exposure measures, duration of exposure to acrylamide, intensity of exposure to acrylamide, and cumulative exposure to acrylamide. The exposure categories for cumulative expo-

Table 7 Observed deaths and SMRs for selected cancer sites by duration of employment, time since first employment, and measures of exposure to acrylamide, all US workers, 1950-94, local county comparisons

\begin{tabular}{|c|c|c|c|c|c|c|c|c|c|c|c|c|}
\hline & \multicolumn{3}{|c|}{ Oesophagus } & \multicolumn{3}{|c|}{ Rectum } & \multicolumn{3}{|c|}{ Pancreas } & \multicolumn{3}{|c|}{ Kidney } \\
\hline & Obs & $S M R$ & $95 \% C I$ & Obs & $S M R$ & $95 \% C I$ & Obs & $S M R$ & $95 \% C I$ & $O b s$ & $S M R$ & $95 \% C I$ \\
\hline \multicolumn{13}{|c|}{ Duration of employment (y): } \\
\hline$<1$ & 12 & 0.84 & 0.43 to 1.46 & 5 & 0.51 & 0.16 to 1.18 & 17 & 0.87 & 0.51 to 1.39 & 8 & 0.79 & 0.34 to 1.55 \\
\hline $1-14$ & 9 & 0.95 & 0.43 to 1.80 & 12 & 1.37 & 0.71 to 2.39 & 15 & 0.95 & 0.53 to 1.57 & 7 & 0.86 & 0.35 to 1.78 \\
\hline$\geqslant 15$ & 10 & 1.60 & 0.77 to 2.94 & 5 & 0.86 & 0.28 to 2.02 & 12 & 1.19 & 0.61 to 2.08 & 7 & 1.36 & 0.55 to 2.79 \\
\hline \multicolumn{13}{|c|}{ Time since first employment (y): } \\
\hline$<20$ & 3 & 0.69 & 0.14 to 2.01 & 3 & 0.71 & 0.15 to 2.07 & 4 & 0.66 & 0.18 to 1.68 & 2 & 0.58 & 0.01 to 2.09 \\
\hline $20-9$ & 6 & 0.80 & 0.29 to 1.73 & 5 & 0.85 & 0.28 to 1.98 & 11 & 1.08 & 0.54 to 1.92 & 3 & 0.54 & 0.11 to 1.58 \\
\hline$\geqslant 30$ & 22 & 1.21 & 0.76 to 1.83 & 14 & 0.98 & 0.53 to 1.64 & 29 & 1.00 & 0.67 to 1.44 & 17 & 1.18 & 0.69 to 1.89 \\
\hline \multicolumn{13}{|c|}{ Duration of exposure (y): } \\
\hline Unexposed & 24 & 0.96 & 0.61 to 1.42 & 17 & 0.82 & 0.48 to 1.32 & 30 & 0.80 & 0.54 to 1.14 & 16 & 0.84 & 0.48 to 1.37 \\
\hline $0.001-4.999$ & 4 & 1.63 & 0.45 to 4.18 & 3 & 1.92 & 0.40 to 5.61 & 5 & 1.46 & 0.47 to 3.41 & 2 & 0.99 & 0.12 to 3.59 \\
\hline $5-19$ & 3 & 1.80 & 0.37 to 5.26 & 1 & 0.71 & 0.02 to 3.96 & 5 & 1.79 & 0.58 to 4.17 & 3 & 1.88 & 0.39 to 5.48 \\
\hline$\geqslant 20$ & 0 & - & 0.00 to 4.10 & 1 & 1.20 & 0.03 to 6.70 & 4 & 2.42 & 0.66 to 6.19 & 1 & 1.18 & 0.03 to 6.56 \\
\hline \multicolumn{13}{|c|}{ Cumulative exposure $\left(\mathrm{mg} / \mathrm{m}^{3} \cdot \mathrm{y}\right)$ : } \\
\hline$<.001$ & 24 & 0.96 & 0.61 to 1.42 & 17 & 0.82 & 0.48 to 1.32 & 30 & 0.80 & 0.54 to 1.14 & 16 & 0.84 & 0.48 to 1.37 \\
\hline $0.001-0.029$ & 2 & 2.58 & 0.31 to 9.30 & 1 & 2.31 & 0.06 to 12.88 & 3 & 2.77 & 0.57 to 8.09 & 1 & 1.45 & 0.04 to 8.08 \\
\hline $0.03-0.29$ & 3 & 1.70 & 0.35 to 4.97 & 2 & 1.73 & 0.21 to 6.23 & 2 & 0.73 & 0.09 to 2.64 & 2 & 1.17 & 0.14 to 4.23 \\
\hline$\geqslant 0.30$ & 2 & 0.82 & 0.10 to 2.98 & 2 & 0.92 & 0.11 to 3.31 & 9 & $2.26^{\star}$ & 1.03 to 4.29 & 3 & 1.49 & 0.31 to 4.35 \\
\hline \multicolumn{13}{|c|}{ Mean intensity of exposure $\left(\mathrm{mg} / \mathrm{m}^{3}\right)$ : } \\
\hline Unexposed & 24 & 0.96 & 0.61 to 1.42 & 17 & 0.82 & 0.48 to 1.32 & 30 & 0.80 & 0.54 to 1.14 & 16 & 0.84 & 0.48 to 1.37 \\
\hline $0.001-0.019$ & 2 & 1.37 & 0.17 to 4.95 & 2 & 2.12 & 0.26 to 7.65 & 4 & 1.69 & 0.46 to 4.32 & 1 & 0.66 & 0.02 to 3.66 \\
\hline $0.02-0.29$ & 3 & 1.53 & 0.32 to 4.47 & 0 & - & 0.00 to 2.03 & 5 & 1.50 & 0.49 to 3.49 & 3 & 1.71 & 0.35 to 5.01 \\
\hline$\geqslant 0.30$ & 2 & 1.26 & 0.15 to 4.53 & 3 & 2.89 & 0.60 to 8.43 & 5 & 2.31 & 0.75 to 5.40 & 2 & 1.68 & 0.20 to 6.08 \\
\hline
\end{tabular}

${ }^{\star} \mathrm{p}<0.05$. 
sure to acrylamide are those used in the original study. ${ }^{1}$ To help discern trends in SMRs, categories for the other variables were chosen to most evenly distribute the numbers of observed deaths simultaneously across the cancer sites examined.

For duration of exposure and time since first exposure to acrylamide, SMRs are generally smallest in the lowest categories. The SMRs for oesophageal cancer increased monotonically with increasing values of both duration of exposure and time since first exposure to acrylamide. Table 7 shows no consistent evidence of an increased risk for cancer mortality associated with exposure to acrylamide, except for pancreatic cancer, where we found a significant $(\mathrm{p}<0.05)$ 2.26-fold risk (95\% CI 1.03 to 4.29 ) in mortality among workers with a cumulative exposure to acrylamide of $\geqslant 0.30 \mathrm{mg} / \mathrm{m}^{3}$.years. Although a monotonically increasing risk with duration of exposure to acrylamide was found, none was found with cumulative exposure to acrylamide. An increased, non-significant 2.77-fold risk (95\% CI 0.51 to 8.09 ) among workers was detected in the lowest cumulative exposure category. Lagged cumulative exposure to acrylamide (not shown) for periods of 5,10 , and 20 years produced a similar pattern of findings as noted in table 7 .
RISK OF CANCER OF THE RESPIRATORY SYSTEM RELATIVE TO EXPOSURE TO ACRYLAMIDE AND

MURIATIC ACID

We fitted RR regression models for cancer of the respiratory system with the subset of the cohort that had potential exposure to muriatic acid (Warners plant workers hired before 1957). All models were based on 276 cases of cancer of the respiratory system (16 exposed to muriatic acid) and 5923 controls, and were adjusted for age and calendar time. In the univariate models, only smoking (characterised as: never, ever, unknown) was a significant predictor of cancer of the respiratory system risk with RRs of $1.00,8.72,7.34$, respectively. None of the variables considered, including the categorical muriatic acid or exposure to acrylamides, was a significant predictor of risk of cancer of the respiratory system. Workers exposed to muriatic acid had a non-significant 1.50 -fold (95\% CI 0.86 to 2.59 ) risk of cancer of the respiratory system compared with workers unexposed to muriatic acid. Models that included an exposure variable representing the joint effects of muriatic acid and exposure to acrylamide had no significant RRs or heterogeneity in risks of cancer of the respiratory system across the joint effects considered (results not shown).

Table 8 Summary of relative risk regression analysis for cancer of the pancreas, US plants, 1925-94

\begin{tabular}{|c|c|c|c|c|c|c|}
\hline \multirow[b]{2}{*}{ Variable } & \multirow[b]{2}{*}{ Category } & \multirow[b]{2}{*}{ Deaths } & \multicolumn{4}{|c|}{ US plants (44 cases, 10261 non-cases) } \\
\hline & & & Risk ratio & $95 \% C I$ & Global test $(d f)$ & Test for trend $d^{\star}(d f)$ \\
\hline \multicolumn{7}{|l|}{ Univariate models $\dagger$} \\
\hline \multirow[t]{2}{*}{ Race } & White & 39 & 1.00 & & & \\
\hline & Non-white & 5 & 0.86 & 0.34 to 2.20 & $0.105(1) \mathrm{p}=0.746$ & - \\
\hline \multirow[t]{4}{*}{ Year of hire } & $1925-39$ & 10 & 1.00 & & & \\
\hline & $1940-49$ & 18 & 1.09 & 0.48 to 2.49 & & \\
\hline & $1950-59$ & 12 & 1.10 & 0.44 to 2.78 & & \\
\hline & $1960-73$ & 4 & 1.59 & 0.40 to 6.36 & $0.405(3) \mathrm{p}=0.939$ & - \\
\hline \multirow[t]{3}{*}{ Duration of employment (y) } & $<1$ & 17 & 1.00 & & & \\
\hline & $1-14$ & 15 & 1.11 & 0.55 to 2.24 & & \\
\hline & $\geqslant 15$ & 12 & 1.39 & 0.66 to 2.96 & $0.738(2) \mathrm{p}=0.692$ & - \\
\hline \multirow[t]{3}{*}{ Time since first employment (y) } & $<20$ & 4 & 1.00 & & & \\
\hline & $20-29$ & 11 & 1.48 & 0.38 to 5.73 & & \\
\hline & $\geqslant 30$ & 29 & 1.28 & 0.32 to 5.15 & 0.378 (2) $\mathrm{p}=0.828$ & - \\
\hline \multirow[t]{3}{*}{ Smoking $\neq$} & Never & 0 & 1.00 & & & \\
\hline & Ever & 12 & 4.96 & 0.82 to infinity & & \\
\hline & Unknown & 32 & 3.59 & 0.64 to infinity & 3.79 (2) $\mathrm{p}=0.145$ & - \\
\hline \multirow{3}{*}{ Time since first exposure (y) } & $<20$ & 34 & 1.00 & & & \\
\hline & $20-29$ & 5 & 2.19 & 0.84 to 5.73 & & \\
\hline & $\geqslant 30$ & 5 & 2.54 & 0.95 to 6.80 & $4.58(2) \mathrm{p}=0.101$ & $4.22(1) \mathrm{p}=0.040$ \\
\hline \multirow[t]{4}{*}{ Duration of exposure (y) } & $<0.001$ & 30 & 1.00 & & & \\
\hline & $0.001-<5$ & 5 & 1.73 & 0.64 to 4.60 & & \\
\hline & $5-19$ & 5 & 2.01 & 0.78 to 5.23 & & \\
\hline & $\geqslant 20$ & 4 & 2.37 & 0.82 to 6.82 & 4.161 (3) $\mathrm{p}=0.245$ & 3.91 (1) $\mathrm{p}=0.048$ \\
\hline \multirow[t]{4}{*}{ Cumulative exposure $\left(\mathrm{mg} / \mathrm{m}^{3} \cdot \mathrm{y}\right)$} & $<0.001$ & 30 & 1.00 & & & \\
\hline & $0.001-<0.03$ & 3 & 3.14 & 0.92 to 10.71 & & \\
\hline & $0.03-<0.30$ & 2 & 0.77 & 0.18 to 3.26 & & \\
\hline & $\geqslant 0.30$ & 9 & $2.63^{\star}$ & 1.23 to 5.60 & 7.69 (3) $\mathrm{p}=0.053$ & - \\
\hline \multirow{4}{*}{ Mean intemsity of exposure $\left(\mathrm{mg} / \mathrm{m}^{3}\right)$} & $<0.001$ & 30 & 1.00 & & & \\
\hline & $0.001-0.02$ & 4 & 1.77 & 0.61 to 5.12 & & \\
\hline & $0.02-<0.30$ & 5 & 1.67 & 0.64 to 4.34 & & \\
\hline & $\geqslant 0.30$ & 5 & $2.86^{\star}$ & 1.08 to 7.56 & 4.74 (3) $\mathrm{p}=0.192$ & - \\
\hline \multicolumn{7}{|l|}{ Bivariable models: } \\
\hline \multirow{4}{*}{ Cumulative exposure $\left(\mathrm{mg} / \mathrm{m}^{3} \cdot \mathrm{y}\right)$} & $<0.001$ & 30 & 1.00 & & & \\
\hline & $0.001-<0.03$ & 3 & 2.51 & 0.63 to 9.92 & & \\
\hline & $0.03-<0.30$ & 2 & 0.57 & 0.11 to 2.99 & & \\
\hline & $\geqslant 0.30$ & 9 & 1.75 & 0.48 to 6.39 & 3.77 (3) $p=0.287$ & - \\
\hline \multirow{4}{*}{ Mean intemsity of exposure $\left(\mathrm{mg} / \mathrm{m}^{3}\right)$} & $<0.001$ & 30 & 1.00 & & & \\
\hline & $0.001-<0.02$ & 4 & 1.27 & 0.34 to 4.78 & & \\
\hline & $0.02-<0.30$ & 5 & 1.05 & 0.26 to 4.18 & & \\
\hline & $\geqslant 0.30$ & 5 & 1.94 & 0.52 to 7.22 & $1.18(3) \mathrm{p}=0.759$ & - \\
\hline
\end{tabular}

${ }^{\star} \mathrm{p}<.05$. †Trend tests performed only on exposure variables exhibiting a monotonic increase or decrease in parameter estimates. $\neq$ Risk sets matched on exact age and year of birth. $§ \operatorname{LogX}$ act used to model smoking due to sparse data problems. $\uparrow$ Risk sets matched on exact age and year of birth, models adjusted for time since first exposure to acrylamide. 
EXPLORATORY RR REGRESSION ANALYSIS

Table 8 shows the RR regression models relating internal cohort rates for pancreatic cancer to the potential confounding variables of interest and the categorical measures of exposure to acrylamide. The number of deaths observed, the estimated RR (95\% CI), and the global test (of main effect) $\mathrm{p}$ value and a trend test $\mathrm{p}$ value, if warranted (monotonic increasing or decreasing pattern of exposure estimates) are shown for each category of the variables considered. The category used as baseline always has an $R R$ value of 1.0; individual RRs are significant if their $95 \%$ CIs do not contain 1.0. All models are based on 44 cases and 10261 controls and adjusted for age and calendar time.

The top section of table 8 shows that none of the potential confounding variables considered is a significant predictor of risk of pancreatic cancer. Smoking history and time since first exposure to acrylamide had relatively low global test $\mathrm{p}$ values $(0.145$ and 0.101 , respectively) and RRs $>2.0$ in the non-baseline categories. Due to sparse data, the model for smoking history was fitted with the exact conditional (stratified) logistic regression program LogXact. ${ }^{16}$ Time since first exposure to acrylamide had a significant $(\mathrm{p}=0.040)$ positive monotonic trend in the parameter estimates.

The univariate models of the three measures of exposure to acrylamide show a pattern of RRs qualitatively similar to the pattern of SMRs in table 7 . The RRs are generally larger than the corresponding SMRs, due to the $20 \%$ deficit in risk of pancreatic cancer among workers in the lowest exposure categories (table 7) that serves as the baseline for the RR models. Table 8 shows that duration of exposure to acrylamide has a significant $(p=0.048)$ monotonic increase in the parameter estimates with increasing duration of exposure to acrylamide. Table 8 also shows that cumulative exposure to acrylamide is a predictor of pancreatic cancer risk of borderline significance $(p=0.053)$, although the increase in RRs with increasing exposure to acrylamide is not monotonic. The RRs for the highest exposure categories of both cumulative exposure to acrylamide and intensity of exposure to acrylamide are significant $(\mathrm{p}<0.05)$.

The bottom of table 8 shows models for cumulative exposure to acrylamide and intensity of exposure to acrylamide, adjusted for the time since first exposure to acrylamide. Because of the sparse data for smoking history (zero non-smoking cases), models adjusted for smoking history would not converge. The adjusted models show a pattern of RRs qualitatively similar to their univariate counterparts; however, RRs are uniformly lower, suggesting positive confounding by time since first exposure to acrylamide. Cumulative exposure to acrylamide is no longer a significant predictor of pancreatic cancer in the adjusted models, and the RRs for the highest exposure categories of both cumulative exposure to acrylamide and intensity of exposure to acrylamide are no longer significant. Lagged analyses $(5,10$, and 20 years) with other categories of cumulative exposure to acrylamide produced a pattern of RRs for cumulative exposure to acrylamide qualitatively similar to those shown in table 8 .

\section{Discussion and conclusions}

The overall mortality patterns found in the 11 year follow up period indicated a significant reduced mortality risk from all causes combined and all cancer sites combined. A similar pattern was noted for the entire 1925-94 study period. This favourable mortality pattern is probably influenced in part by the healthy worker effect, a relative absence of deleterious health risks relative to employment, and the effects of continuing employment with its many benefits - such as improved health care and quality of life.

For the 1925-94 study period, we found no significant overall risk or plant specific risk for the cancer sites of initial interest: cancer of the brain and other parts of the CNS, thyroid and other endocrine glands, testis and other male genital organs, and cancer of the respiratory system. However, among the workers exposed to acrylamide, except for cancer of the respiratory system, the few observed deaths for the sites of initial interest resulted in low statistical power to detect important excesses and precluded a detailed examination of exposureresponse.

Although not significant, we found increased SMRs for cancer of the thyroid gland (and the larger category, thyroid gland and other endocrine glands) among several cohort subgroups, including a fourfold risk among workers exposed to acrylamide and a twofold risk among unexposed workers. This pattern, based on six cases, with a decreasing SMR across the update periods does not support a causal association between exposure to acrylamide and cancer of the thyroid and suggests that other unmeasured occupational or nonoccupational factors may be involved with these excesses. Additional cohort follow up will help to elucidate these possibilities.

An examination of the cluster of suspected cases of cancer of the respiratory system among Warners employees ${ }^{1}$ identified an additional five cases of cancer of the respiratory system among workers with potential exposure to muriatic acid before 1957. Although there is some suggestion that employees with exposure to muriatic acid with and without exposure to acrylamide are at increased risk of cancer of the respiratory system, the limited number of observed deaths $(n=16)$ and incomplete data on smoking history preclude definitive conclusions. Our modelling of cancer of the respiratory system risk showed no evidence of a joint effect of muriatic acid and exposure to acrylamide.

In an exploratory exposure-response analysis of SMRs, we found a non-significant monotonically increased risk of pancreatic cancer relative to duration of exposure to acrylamide. No increased risk pattern was found for either cumulative exposure or intensity of exposure to acrylamide, although a significant 2.26-fold risk was found among workers in the highest 
category of cumulative exposure to acrylamide $\left(\geqslant 0.30 \mathrm{mg} / \mathrm{m}^{3}\right.$.years). All 14 cases of pancreatic cancer exposed to acrylamide were born before 1939 and hired before 1966. No consistent pattern was readily apparent when individual work history records were examined. A non-significantly increased risk of pancreatic cancer was found in the original study among workers exposed to acrylamide, but there was no trend with increasing exposure. ${ }^{1}$

Modelling results showed a pattern of RRs qualitatively similar to those found in the SMR analysis and suggested potential confounding with time since first exposure to acrylamide and with a history of smoking. Smoking is the most consistent risk factor for pancreatic cancer, associated with a greater than twofold increased risk. ${ }^{17}$ In models adjusted for time since first exposure to acrylamide, we found less evidence of an exposure-response relation for cumulative exposure and intensity of exposure to acrylamide; RRs for these measures decreased to non-significant levels suggesting that this variable acted as a positive confounding factor. Although our inclusion of time since first exposure to acrylamide as a co-factor in models with cumulative exposure to acrylamide and intensity of exposure to acrylamide is statistically appropriate and biologically relevant, some bias may have resulted in the models for cumulative exposure to acrylamide due to the collinearity between the two time dependent factors.

Given the absence of a significant absolute risk, the weak evidence for an exposureresponse relation and the inability to consider smoking adequately, as a potential confounding factor, our findings for cancer of the pancreas should be interpreted with caution, in the context of an exploratory analysis to generate hypotheses. This is supported by a recent review by Anderson et al who concluded that an occupational aetiology was probably unimportant, given the breadth of workplace experiences examined with few positive findings. ${ }^{17}$ Additional follow up may elucidate whether the association is spurious or warrants further examination. Among the other cancer sites examined in the exploratory analysis (oesophagus, rectum, and kidney), we found increased SMRs for some categories of exposure to acrylamide, but little evidence of an exposureresponse relation.

Nearly half of the cohort were short term workers, a characteristic not presented in the original study findings. About $50 \%$ of the acrylamide cohort worked $>1$ year and only 1936 $(23 \%)$ worked $\geqslant 10$ years. Consequently, most of the cohort had minimal potential for exposure to acrylamide or were exposed to low levels. Contrary to many other occupational cohort studies, short term workers did not show a differential mortality pattern often associated with increased mortality for both malignant and non-malignant diseases. The long duration of follow up in this study may have mitigated the mortality influence of short term workers.

The limitations of our acrylamide studynamely a large proportion of short term workers - skewed distribution of person-years with respect to duration of exposure, low exposures, and incomplete smoking data, are found in many occupational cohort studies. As such, many studies restrict cohort entry to long term employees. Had short term employees been excluded in the 1994 update, valuable data would have been lost - for example, the cancer of the respiratory system cluster. Potential selection bias from workers lost to follow up may be operating, but the effects would be minimal due to the small percentage of workers involved. Because we did not adjust $\mathrm{p}$ values for multiple comparisons, some of our significant SMRs and RRs may be simply chance occurrences.

Our study also has low statistical power to detect excess risks for many cancer sites of initial interest, especially in the subgroup analyses. For example, for the combined 1925-94 study period, our study has the following power to detect twofold or greater risks in mortality (at the $5 \%$ one sided significance level): cancer of the brain and other parts of the CNS (0.25), thyroid gland (0.18), and testis and other male genital organs $(0.41)$. On the other hand, the corresponding power to detect cancer of the respiratory system of 0.87 is excellent. Although power is not relevant for the excess of pancreatic cancer identified in the exploratory analysis, a future study of this size would have a power of nearly $100 \%$ to detect a twofold or greater excess.

By comparison, our acrylamide study has many methodological strengths that include: large cohort size; long observation period; good death certificate ascertainment for the United States plants; sufficient statistical power to detect meaningful excesses for many categories of cause of death; ample duration of exposure (many years of acrylamide production); quantitative measures of exposure to acrylamide and the use of local county comparison rates and robust modelling of internal cohort rates, a methodological improvement on the original 1989 report.

In summary, this study has many strengths and is the most definitive study of the human carcinogenic potential of exposure to acrylamide conducted to date. The contribution of 1115 additional deaths and nearly 60000 person-years over the 11 year follow up corroborate the original cohort study findings - namely, little evidence of a causal relation between exposure to acrylamide and mortality from any cancer sites, including those of initial interest. An increased risk of mortality from cancer of the respiratory system, noted in the original study, decreased considerably in the update period and remains only slightly increased among workers exposed and unexposed to acrylamide. Additional follow up of the cohort may elucidate whether the excess of thyroid cancer and the association found between exposure to acrylamide and pancreatic cancer in an exploratory analysis are spurious or warrant further examination.

This work was supported by Cytec Industries. We acknowledge Steve Sefcik, Consultant and Al Johnson of Cytec Industries who provided computer programming support. 
1 Collins JJ, Swaen GH, Marsh GM, et al. Mortality patterns among workers exposed to acrylamide. $\mathcal{f}$ Occup Med among workers

2 Johnson KA, Gorzinski SJ, Bodner KM, et al. Chronic toxicity and oncogenicity study of acrylamide incorporated in the drinking water of Fischer 344 rats. Toxicol Appl Pharmacol 1986;85:154-68.

3 Bull RJ, Robinson M, Laurie RD, et al. Carcinogenic effects of acrylamide in Sencar and A/J mice. Cancer Res 1984;44 107-11.

4 Sobel W, Bond GG, Parson TW, et al. Acrylamide cohort mortality study. Br f Ind Med 1986;43:785-8.

5 Schall LS, Marsh GM, Henderson VL. A two-stage protocol for verifying vital status in large historical cohort studies. $f$ Occup Environ Med 1997;39:1097-102. 6Marsh GM, Preininger ME OCMAP. a user-oriented occupational cohort mortality analysis program. American Statistician 1980;34: 245-6.

7 Marsh GM, Ehland J, Paik M, et al. OCMAP/PC: a user-oriented cohort mortality analysis program for the

8 Marsh GM, Youk AO, Sefcik SS, et al. OCMAP-PLUS: a program for the comprehensive analysis of occupational cohort data. F Occup Environ Med 1998;40:351-62.

9 Monson RR. Analysis of relative survival and proportional mortality Computers and Biomedical Research 1974:7·325.

10 Marsh GM, Ehland J, Sefcik SS. Mortality and population data system [technical report]. Pittsburgh, PA: University of Pittsburgh, Department of Biostatistics, 1997.

11 Caplan RJ, Marsh GM, Enterline PE. A generalized effective exposure modeling program for assessing doseresponse in epidemiologic investigations. Computers and Biomedical Research 1984;16:587-96.

12 Breslow NE, Day NE. The design and analysis of cohort studies. Statistical methods in cancer research. Vol II. Lyon: International Agency for Research on Cancer, Oxford University Press, 1987. (IARC Sci Publ No 82.)

13 Cox DR. Regression models and life tables [with discussion]. Fournal of the Royal Statistical Society 1972;34:187220.

14 Cox DR. Partial likelihood. Biometrika 1975;62:269-76.

15 EGRET, Version 1.02.09. Seattle, WA: Statistics and Epidemiology Research Corporation, 1991.

16 Cytel Software. LogXact turbo: software for exact conditional logistic regression. Cambridge, MA: Cytel Software, 1993.

17 Anderson KE, Poter JD, Mack TM. Pancreatic cancer (chapter 35). In: Schottenfeld D, Fraumeni JF Jr, eds. Cancer epidemiology and prevention, 2nd ed. New York: Oxford University Press, 1996.

\section{Correspondence and editorials}

Occupational and Environmental Medicine welcomes correspondence relating to any of the material appearing in the journal. Results from preliminary or small scale studies may also be published in the correspondence column if this seems appropriate. Letters should be not more than 500 words in length and contain a minimum of references. Tables and figures should be kept to an absolute minimum. Letters are accepted on the understanding that they be subject to editorial revision and shortening.

The journal also publishes editorials which are normally specially commissioned. The Editor welcomes suggestions regarding suitable topics; those wishing to submit an editorial, however, should do so only after discussion with the Editor. 